Beskattningen af utdelning å aktier och valet af "inkomstperiod" vid taxeringen till inkomstskatt

Author(s): D. D.

Source: Ekonomisk Tidskrift, Årg. 7 (1905), pp. 465-469

Published by: Wiley on behalf of The Scandinavian Journal of Economics

Stable URL: http://www.jstor.org/stable/3437019

Accessed: 01-06-2016 08:16 UTC

Your use of the JSTOR archive indicates your acceptance of the Terms \& Conditions of Use, available at

http://about.jstor.org/terms

JSTOR is a not-for-profit service that helps scholars, researchers, and students discover, use, and build upon a wide range of content in a trusted digital archive. We use information technology and tools to increase productivity and facilitate new forms of scholarship. For more information about JSTOR, please contact support@jstor.org.

The Scandinavian Journal of Economics, Wiley are collaborating with JSTOR to digitize, preserve and extend access to Ekonomisk Tidskrift 


\section{Beskattningen af utdelning å aktier och valet af "inkomstperiod" vid taxeringen till inkomstskatt.}

Som bekant pågår för närvarande en officiell undersökning om lämpligheten och utförbarheten att utbyta bestämmelsen i nuvarande bevillnings- och inkomstskatteförordningar, att det är det löpande årets inkomst, som beskattas, emot bestämmelsen, att beskattningen skall gälla det föregående årets inkomst. Lämpligheten af denna förändring har jag sökt uppvisa $\mathrm{i}$ en tidigare uppsats $\mathrm{i}$ denna tidskrift. ${ }^{1}$ Uppgiften för dessa rader är att göra ett tillägg till hvad jag där anfört, hvilket torde ytterligare styrka riktigheten af den uppfattning, jag där förfäktade.

Om, såsom ju nästan alltid sker, utdelningen från aktiebolag äger rum under året efter det, hvarunder aktiebolaget förvärfvat denna inkomst, blifva aktieägarne beskattade för utdelningen från bolaget ett år efter det, hvarunder aktiebolaget själft beskattas för den vinst, hvarur utdelningen bestrides. Den vinst, som ett aktiebolag skördar under år 1905, beskattas hos aktiebolaget samma år. Men den utdelning, som sker till aktieägarne ur sagda vinst, beskattas hos aktieägarne gemenligen först I906. Om nu bolaget upplöses i slutet af 1906 och fördelningen af aktiebolagets tillgångar bland aktieägarne sker samma år, ha aktieägarne under detta år faktiskt erhållit utdelning för två af aktiebolagets verksamhetsår, nämligen i början af året utdelning af aktiebolagets vinst under 1905 och i slutet af året utdelning af aktiebolagets vinst under 1906. Frågan blir nu först: huru skola aktieägarne 1906 taxeras för inkomst af utdelning från ifrågavarande bolag? Svaret på denna fråga lärer väl ej kunna blifva annat än

\footnotetext{
1 Årgången 19,03, sid. 394 o. ff.
} 
detta: de skola taxeras för det belopp, hvartill deras under 1905 utfallande utdelning uppgått, d. v. s. de beskattas för år 1906 blott för utdelning af ett års vinst. Nästa fråga blir: kunna aktieägarne år 1907 taxeras för inkomst af utdelning från aktiebolaget $i$ fråga? Huru denna fråga skall besvaras, är delvis omtvistadt. Men huru man i de omtvistade fallen än besvarar denna fråga, så kommer man till ett $\mathrm{i}$ det hela orimligt resultat. Detta skall jag nu visa genom att till behandling upptaga de olika svar på nyssnämnda fråga, som skulle kunna ifrågasättas.

Ett svar vore, att aktieägarne icke kunna år 1907 beskattas för utdelning från det upplösta aktiebolaget. Skälet härtill skulle vara, att de I907 icke längre inneha den inkomstkälla, hvarur inkomsten erhållits, nämligen aktier i det upplösta aktiebolaget. De aktieägare, som t. ex. för de penningar, de vid aktiebolagets likvidering erhöllo, köpa en fastighet eller en rörelse, skola för år 1907 taxeras för det belopp, hvartill inkomsten af denna rörelse eller denna fastighet under år 1907 sannolikt, resp. efter viss beräkning kommer att uppgå, men kunna icke taxeras för den utdelning, de under 1906 erhållit från det upplösta aktiebolaget. Därom torde alla vara ense. Oenigheten uppstår först, om aktieägarne för de erhållna medlen förskaffa sig ny inkomst af kapital, d. v. s. placera medlen antingen $\mathrm{i}$ räntebärande fordringar eller $\mathrm{i}$ aktier $\mathrm{i}$ andra bolag. Användes det första placeringssättet, lär väl svaret på frågan böra blifva detsamma som nyss; d. v. s. taxering skall ske till det belopp, hvartill inkomsten sannolikt kommer att under 1907 uppgå. Att i detta fall taxera de forna aktieägarne i det upplösta aktiebolaget för inkomst af den räntebärande kapitaltillgången till det belopp, hvartill utdelningen från det upplösta aktiebolaget under 1906 uppgått, bör väl ej kunna anses stå i öfverensstämmelse med de principer, hvarpå våra beskattningsförordningar äro byggda. Enligt bevillningsförordningen skola desse skattskyldige otvifvelaktigt taxeras till det belopp, hvartill ränteinkomsten under år 1907 sannolikt kommer att uppgå. Men då det icke lär kunna gå an, att upptaga inkomsten af samma räntebärande kapital till olika belopp enligt bevillningsförordningen och enligt inkomstskatteförordningen, kan vid taxeringen till inkomstskatten inkomsten af det räntebärande kapitalet ej upptagas till det belopp, hvartill utdelningen från det upplösta aktiebolaget under 1906 uppgick. Besvaras frågan på detta sätt, uppstår den oegentligheten, att aktieägarne $i$ det upplösta bolaget gå fria från skatt för utdelningen af aktiebolagets vinst för ett år. Antag t. ex., att det upplösta bolaget börjat sin rörelse 1897 och denna sålunda drifvits under tio år, så ha aktie- 
ägarne endast beskattats för 9 års vinster. Första året, de beskattas för utdelning från bolaget, är I898, och sista året 1906. Detta blir blott 9 år, och för hvart och ett af dessa år ha de blott beskattats för utdelning från vinsten af ett års rörelse, sålunda blott för 9 vinstår, fastän de faktiskt uppburit utdelning af vinsten ur aktiebolagets rörelse under alla de Io åren.

I en artikel i denna tidskrift för år 1903 med titel "Några frågor rörande beskattningen af aktiebolags vinst enligt inkomstskatteförordningen» behandlade jag sid. $36 \mathrm{r}$ o. ff. frågan, huruvida såsom beskattningsbar utdelning af aktier enligt inkomstskatteförordningen skulle upptagas blott utdelning, som härrörde från aktiebolagets beskattningsbara inkomst, eller äfven den utdelning, som härflöt ur vinst, som icke betraktas såsom beskattningsbar inkomst för aktiebolaget. Om t. ex. ett industriellt aktiebolag, hvars fabrik är centralt belägen i en stad med höga tomtpriser, beslutar att sälja fabrikstomten och flytta fabriken ut på landsbygden och utdelar till aktieägarne den vinst, som uppstått på tomtens försäljning, så föreligger utdelning till aktieägarne af en aktiebolagets vinst, som ej inräknas i aktiebolagets beskattningsbara inkomst. I nämnda uppsats medgaf jag, att denna fråga är svår att lösa, men ansåg, att öfvervägande skäl torde tala för att icke inräkna sådan inkomst i aktieägarnes beskattningsbara inkomster. Bodin och Palmgren åter ha $\mathrm{i}$ tredje upplagan af sitt arbete »Själfdeklaration» sid. 97 uttalat, att den motsatta uppfattningen torde vara den rätta. De yttra där: „Vidare synes det vara utan betydelse, om vinstmedlen $\mathrm{i}$ bolagets hand varit att anse såsom beskattningsbar inkomst eller icke. Om exempelvis till utdelningen användas medel, hvilka härflyta från en icke beskattningsbar konjunkturvinst, såsom vinst på försäljning af fast egendom eller värdepapper, hvilka af bolaget icke förvärfvats i spekulationssyfte och innehafts en längre tid, lärer utdelningen i alla fall vara beskattningsbar hos aktieägaren.» Det torde på grund häraf, trots det sväfvande uttrycket »lärer», vara antagligt, att detta får anses vara den ståndpunkt, som praxis $\mathrm{f}$. $\mathrm{n}$. intager.

Ansluter man sig till Bodins och Palmgrens tolkning, blifver oegentligheten än större, enär aktieägarna komma att undgå beskattning för de $\mathrm{i}$ aktiebolagets hand icke beskattningsbara konjunkturvinster, som bolaget skördat under föregående år och reserverat eller som bolaget vunnit under det sista året. Särskildt de under sista året skördade konjunkturvinsterna. som ju ej kunna utdelas förr än tidigast under samma år och för hvilka alltid beskattning sålunda skulle undgås, kunna, såsom 
af åtskilliga aftärstransaktioner under senaste åren framgår, ofta vara synnerligen betydliga.

Jag anknyter nu åter vid hvad jag yttrade sid. 466. Om aktieägarne i det upplösta bolaget för de medel, de erhålla från bolaget vid upplösningen, förvärfva aktier $\mathrm{i}$ andra bolag, så äro två alternativa svar på den sid. 466 uppställda frågan möjliga. Det ena är, att äfven i detta fall samma regel skall tillämpas som $i$ de föregående fallen, eller att aktieägarne i det upplösta aktiebolaget skola för år 1907 taxeras för det belopp, hvartill deras utdelning från de nya aktiebolag, hvari de inträdt, under 1907 kommer att uppgå. Till stöd härför kan anföras, att inkomstkällan genom förvärfvet af andra aktier så väsentligt förändrats, att inkomsten enligt regeln $\mathrm{i}$ inkomstskatteförordningen $\$ 5$ mom. 2 a) skall upptagas med det belopp, hvartill den sannolikt kommer att under 1907 uppgå. Enligt detta alternativ blifva oegentligheterna desamma, som nyss anfördes.

Det andra alternativet är, att man resonnerar så, att då här blott ett utbyte af aktier och sålunda ej någon väsentlig ändring af inkomstkällan ägt rum, så böra aktieägarne $\mathrm{i}$ det upplösta aktiebolaget för år I907 taxeras för inkomst af aktier till det belopp, hvartill deras utdelning från det upplösta bolaget under 1906 uppgick. Enligt detta alternativ uppstår för detta fall ej någon oegentlighet. Antag t. ex., att bolagets rörelse började 1897 och att det upplöses i slutet af 1906, att aktieägaren A. erhållit för hvart och ett af åren 1898-1905 10,000 kronor i utdelning och under 1906 i början af året 10,000 kronor och i slutet af året, i sammanhang med upplösningen, I0,000 kronor, eller sammanlagdt $20,000 \mathrm{kr}$.; att A. i början af 1907 köper andra aktier, för hvilka han under 1907 erhåller i utdelning Io,000 kronor. A. har sålunda för de tio åren I898 -1907 erhållit i utdelningar sammanlagdt IIO,000 kronor, nämligen I0,000 kronor under hvart och ett af de 8 åren I898-1905, 20,000 kronor under 1906 och 10,000 kronor under 1907. A. kommer enligt förevarande alternativ att taxeras för 10,000 kronor under hvart och ett af de 9 åren 1898- 1906 och för 20,000 kronor 1907 , d. v. s. sammanlagdt för I IO,000 kronor.

Men med det sagda äro icke alla oegentligheter uttömda. Det kan tänkas fall, då aktieägare i det upplösta aktiebolaget får erlägga skatt för ett för högt belopp. Antag, att bolaget ej hinner med sin likvidation under 1906, utan att utdelningen af aktiebolagets kapital och vinsttillgångar först kan ske $\mathrm{i}$ början af 1907. För att belysa, hvad som då 
kan komma att ske, använder jag samma exempel som nyss, dock med den modifikationen, att aktieägaren $\mathrm{A}$. för de från bolaget erhållna medlen köper obligationer, som antagas gifva honom en inkomst af 10,000 kronor under 1907. A. uppbär då under åren I898-I907 samma totalinkomst som i det nyssnämnda exemplet, eller I I0,000 kronor. Huru skall han i detta fall taxeras? För hvart och ett af de 9 åren I898-igo6 skall han taxeras för 10,000 kronors inkomst. För år 1907, då han fortfarande uppbär inkomst af aktier $\mathrm{i}$ det upplösta bolaget, skall han taxeras för ett belopp, motsvarande hvad han under 1906 uppburit i utdelning å dessa aktier, eller för 20,000 kronor. Detta gör sammanlagdt I IO,000 kronor. Men dessutom skall han för 1907 taxeras för den inkomst - 10,000 kronor, som han antages få ur sin nya inkomstkälla - obligationerna. Det går ej för sig att 1907 icke taxera honom till inkomstskatt för detta belopp, då han ju otvifvelaktigt måste 1907 taxeras till bevillning för sagda belopp. I detta fall făr A. för åren I898-1907 erlägga skatt för I 20,000 kronor, d. v. s. i själfva verket för ett års inkomst mer än han uppburit.

Alla dessa oegentligheter undvikas tydligen genom att införa den bestämmelsen, att inkomst alltid skall beskattas först året närmast efter det, hvarunder inkomsten uppburits. Och detta är ju ett ytterligare skäl, för att denna princip må af vår skattelagstiftning accepteras.

D. D. 